\title{
EFEITO DA ÉPOCA DE ESTAQUIA, FITORREGULADORES E ÁCIDO BÓRICO NO ENRAIZAMENTO DE ESTACAS DE PORTA-ENXERTOS DE VIDEIRA
}

\author{
S. LEONEL \\ Dep. de Botânica do Instituto de Biociências/UNESP - CEP: 18618-000-Botucatu,SP. \\ J.D. RODRIGUES \\ Prof. Adjunto do Dep. de Botânica do Instituto de Biociências/UNESP - CEP: 18618-000-Botucatu,SP.
}

RFSUMO: Estudaram-se as interações entre os ácidos indol-butírico, alfa-naftaleno-acético e bórico no desenvolvimento de raízes em estacas de porta-enxertos de videira (Vitis vinifera L.). As estacas tinham aproximadamente $25 \mathrm{~cm}$ de comprimento e, necessariamente, 2 gemas, sendo obtidas em três épocas distintas (janeiro, abril e julho) e colocadas para enraizar em bandejas de isopor, tendo vermiculita como substrato, e mantidas sob nebulização. $O$ tratamento constou da imersão de $2,5 \mathrm{~cm}$ da base das estacas em soluções, por um tempo de imersão de 1 minuto. Os tratamentos utilizados corresponderam a: 1.000; 2.000 e 5.000 ppm de IBA; 1.500 e $3.000 \mathrm{ppm}$ de NAA; 150 microgramas $/ \mathrm{ml} \mathrm{de} \mathrm{II}_{3} \mathrm{BO}_{3} ; \mathrm{IBA} 1.000 ; 2.000$ e $5.000+\mathrm{H}_{3} \mathrm{BO}_{3} 150$ microgramas $/ \mathrm{ml}$ e $\mathrm{I}_{2} \mathrm{O}$. Avaliaram-se a porcentagem de enraizamento, o número médio de raízes formadas por estaca e o comprimento médio das raizes (mm) aos 90 dias após a instalação, no mês de julho. O IBA 2.000 ppm propiciou o enraizamento em $88,87 \%$ das estacas, contudo não diferiu estatisticamente da testemunha $\left(\mathrm{H}_{2} \mathrm{O}-61,10 \%\right)$. A melhor época de coleta de estaca para o enraizamento foi 0 mês de julho (inverno).

Descritores: Vitis vinifera, auxinas, enraizamento, estaquia, boro.

\section{EFFECT OF PRUNING TIME, GROWTII REGULATORS AND BORIC ACID ON ROOTING OF GRAPE ROOTSTOCK CUTTINGS}

\begin{abstract}
ARSTRACT: The effects of indolebutyric, naphtalen acetic and boric acids were studied on rooting of grape rootstock cuttings. The cuttings were $25 \mathrm{~cm}$ long with two buds and were taken in three different times (January, April and July). Rooting was carried out in styrofoam trays with vermiculite as substratum and under intermittent mist. Cuttings were imersed up to $2.5 \mathrm{~cm}$ from the base in solutions for one minute. The treatments were: 1,000; 2,000 and $5,000 \mathrm{ppm}$ of $\mathrm{IB} \Lambda ; 1,500$ and $3,000 \mathrm{ppm}$ of $\mathrm{NAA} ; 150$ micrograms $/ \mathrm{ml} \mathrm{II}_{3} \mathrm{BO}_{3} ;$ IBA 1,$000 ; 2,000$ and 5,000 ppm plus $\mathrm{IH}_{3} \mathrm{BO}_{3} 150 \mathrm{micrograms} / \mathrm{ml}$ and $\mathrm{II}_{2} \mathrm{O}$. Rooting percentage, average number of roots per cutting and average length of roots $(\mathrm{mm})$ were evaluated 90 days after planting, in July. IB $\mathrm{A}$ at $\mathbf{2 , 0 0 0} \mathrm{ppm}$ was the best treatment with $\mathbf{8 8 . 8 \%}$ of rooted cuttings. The best time for rooting was July (winter).
\end{abstract}

Key Words: Vitis vinifera, auxins, rooting, cuttings.

\section{INTRODUÇÃO}

A videira é uma fruteira bastante conhecida e divulgada no Brasil, podendo a implantação da cultura ser feita com diferentes objetivos: produção de vinhos, produção de uvas de mesa e produção de passa ao natural.

No Brasil, sua propagação é feita quase que totalmente através da enxertia, pois tal método promove o desenvolvimento de sistema radicular eficiente e também faz com que a muda tenha mais resistência a pragas e doenças, como filoxera e nematóides, entre outras, conforme vários autores citados por SILVA et al. (1986).

De acordo com SANTOS NETO (1973), para a formação de um vinhedo em São Paulo, faz-se o plantio das estacas dos porta-enxertos no lugar definitivo (meses de maio a agosto) ou então, o enraizamento (barbados), para enxertia no inverno do ano seguinte (meses de novembro a dezembro).

Entretanto, autores como SANTOS NETO (1973), PEREIRA et al. (1973), ALVARENGA (1976) e TERRA et al. (1981) relatam que com o plantio dos porta-enxertos diretamente no campo, obtém-se baixa porcentagem de pegamento e, como consequência, um período de dois a três anos para obtenção de mudas, devido às condições impróprias para o enraizamento. Como meio para aumentar a porcentagem de enraizamento de estacas de porta-enxertos, tem sido utilizados alguns reguladores de crescimento sintéticos do grupo das auxinas, os quais são de grande interesse à fruticultura moderna, pois com seu emprego, obtem-se, quase sempre, um aumento na 
porcentagem de estacas enraizadas, conforme o relatado por ALVARENGA (1976), ALCÂNTARA et al. (1983), HARTMANN \& KESTER (1983) e GALVÃO et al. (1987).

$O$ presente trabalho foi conduzido com o objetivo de identificar qual a melhor época do ano para o enraizamento de estacas de porta-enxertos de videira, além de avaliar o efeito da utilização dos fitorreguladores, ácido indol-butírico e alfanaftaleno-acético, aplicados isoladamente ou em conjunto com o ácido bórico, o qual de acordo com ELLIASSON (1978), LEWIS (1980), HIRSCH et al. (1982) e JARVIS et al. (1984), exerce um efeito sinergístico com as auxinas, no desenvolvimento de raízes em estacas de videira (Vitis vinifera $\mathrm{L}$.)

\section{MATERIAL E MÉTODOS}

$O$ experimento foi realizado em câmara de nebulização, sob ripado. As estacas foram retiradas de ramos medianos e terminais de porta-enxertos de videira "Riparia do Traviú" ou "Traviú" (Riparia $x$ Rupestris Cordifolia 106-8), pertencentes ao pomar da Fazenda Experimental Lageado, em três diferentes épocas do ano, correspondente aos meses de janeiro, abril e julho de 1989 , com o objetivo de identificar, de acordo com a fenologia da planta, qual a melhor época do ano para a retirada de estacas, visando o enraizamento.

Posteriormente, as estacas foram uniformizadas com aproximadamente $25 \mathrm{~cm}$ de comprimento e, necessariamente, 2 gemas. A base das estacas foi cortada em bisel, sendo o corte feito logo abaixo de uma gema. Para cada mês de instalação foram utilizadas 400 estacas de porta-enxerto de videira, devidamente identificadas e distribuídas aleatoriamente, sendo cada parcela constituída por 10 estacas, num delineamento inteiramente casualizado, com quatro repetições. Os resultados foram submetidos à análise de variância (teste F), com comparação das médias pelo teste Tukey.

A seguir as estacas foram mergulhadas em soluções contendo auxina ou ácido bórico, ou mistura destes, conforme os tratamentos preconizados, por um minuto, e à cerca de $2,5 \mathrm{~cm}$ da base. Os tratamentos utilizados foram: 1.000 , 2.000 e $5.000 \mathrm{ppm}$ de IBA; 1.500 e $3.000 \mathrm{ppm}$ de $\mathrm{NAA} ; 150$ microgramas $/ \mathrm{ml} \mathrm{de} \mathrm{H}_{3} \mathrm{BO}_{3}$; IBA 1.000 , 2.000 e $5.000 \mathrm{ppm}+\mathrm{H}_{3} \mathrm{BO}_{3} 150$ microgramas $/ \mathrm{ml}$ e $\mathrm{H}_{2} \mathrm{O}$.

Após o tratamento, as estacas foram colocadas para enraizar em bandejas de isopor de 12 cm de profundidade, com 128 células cada uma, tendo, como substrato, vermiculita de granulação média e mantidas sob nebulização intermitente.

A análise dos parâmetros avaliados, porcentagem de enraizamento das estacas, número médio de raízes formadas por estaca e comprimento médio das raízes (mm), foi feita aos 90 dias após a instalação, no mês de julho de 1989.

\section{RESULTADOS E DISCUSSÃO}

\section{Primeira época de instalação (janeiro/1989)}

De acordo com SOUZA et al. (1969), o ciclo vegetativo anual da parreira acompanha de perto a sucessão das quatro estações do ano. Assim, a videira atravessa um período de dormência no inverno, um período de despertar e crescimento na primavera, frutificação no verão e amadurecimento geral no outono. Porém, este ciclo não é rígido; cada espécie e cada variedade tem as suas datas de brotação, florescimento e dormência, que não são forçosamente as mesmas nas diferentes regiōes do país. Dessa forma, existem diversos trabalhos que procuram identificar a melhor época para o enraizamento das estacas de videira.

WEAVER (1982) relata que estacas de folhas caducas, como é o caso da videira, enraizam melhor durante o período de crescimento ativo do que durante a temporada de repouso. Conforme os resultados encontrados por RIBAS \& CONAGIN (1957), a melhor época para o enraizamento da maioria dos porta-enxertos de videira, é de junho até agosto. ALVARENGA \& FORTES (1976) obtiveram uma baixa porcentagem de vingamento no porta-enxerto Kobber, atribuindo tal fato à época inadequada para 0 enraizamento. Os autores supracitados colocaram as estacas para enraizar no mês de agosto, sendo que o mais recomendado seria o mês de junho.

Utilizando-se estacas de figueira (Ficus carica L.), PEREIRA et al. (1973) concluíram que a formação de raízes em estacas dessa espécie diminui com o decorrer da época de estaquia, sendo que nos meses de maio e junho ocorrem as maiores porcentagens de enraizamento.

Os resultados obtidos com a realização deste trabalho permitiram identificar que esta época de verão, onde ocorre a frutificação das videiras, não é favorável para o enraizamento. Observou-se, inicialmente, um escurecimento, perda de folhas, seguidos da morte de praticamente todas as estacas, sendo que não foi verificada brotação de parte aérea 
em quase nenhuma delas. Tal fato, talvez possa ser atribuído às altas temperaturas observadas nesta época do ano, associado às altas concentrações de fitorreguladores empregadas, num tempo de imersão talvez prolongado para esta espécie (Figura 1).

\section{Segunda época de instalação (abril/1989)}

De acordo com KERSTEN (1987), existem diferenças entre as espécies no que se refere à facilidade para a indução das raizes. $O$ autor relata ter sido demonstrado que, quando a concentração de auxinas é relativamente alta ocorre um favorecimento na formação de raízes adventícias, impedindo a formação de gemas. Quando outros constituintes da planta, como as adeninas e cinetinas, encontram-se em níveis relativamente altos, acontece a formação de gemas, inibindo a formação de raízes, sendo que, em proporções quase iguais, ocorre a proliferação de células sem a formação de órgãos.

Segundo FADL \& HARTMANN (1967), gemas de pereira (Pyrus communis L.) cvs Old Home e Bartlet são capazes de emitirem brotações em altas porcentagens no verão e outono, seguidas de baixa porcentagem no inverno. A variação estacional da atividade das gemas, foi observada em ramos lenhosos. A capacidade de enraizamento de estacas destes cultivares é alta no verão e baixa nas outras estações, podendo ser alterada por eliminação de gemas, pois há uma relação entre enraizamento e número de gemas nos ramos.

Também IVANIKA \& PASTYRIK (1978), relataram que em macieira, o número de gemas exerce acentuada influência no enraizamento de estacas de ramos.

Esta segunda época de instalação também pareceu não ser favorável para o enraizamento das estacas de videira, resultado que, por sinal, concorda com a literatura consultada. Diferenças no enraizamento de estacas herbáceas, devidas à época de estaquia foram também obtidas por HARTMANN \& HANSEN (1955), LANPHEAR \& MEAHL (1963) e ZANIN (1985). Todavia, o comportamento das estacas nesta época, não foi semelhante ao mês de janeiro. Estas permaneceram vivas em maior quantidade, havendo inclusive, brotações em algumas e emissão de raízes nos tratamentos com $\mathrm{H}_{2} \mathrm{O}, \mathrm{H}_{3} \mathrm{BO}_{3} 150$ microgramas $/ \mathrm{ml}$ e NAA 1.500 ppm (Figura 1)

\section{Terceira época de instalação (julho/1989)}

Com o presente trabalho, pode detectar-se que a melhor época para o enraizamento de estacas de porta-enxerto de videira "Riparia do Traviú" ou "Traviú" foi o mês de julho. Nesse período, foi observada a totalidade de sobrevivência e uma boa porcentagem de enraizamento das estacas, vindo corroborar a literatura existente na área. Depois de 30 dias da estaquia observou-se uma intensa brotação e posteriormente, aos 90 dias pode detectar-se a formação de raízes nas estacas (Quadro $1)$.

SILVA et al. (1986), plantaram estacas de diferentes porta- enxertos de videira no período de julho a outubro, obtendo resultados diferentes para os porta-enxertos utilizados. Utilizando-se do ácido indol-butírico $2.000 \mathrm{ppm}$, os autores obtiveram os seguintes números de raizes por estaca: cultivar $\mathrm{SO} 4$ $(13,56)$, cultivar 101-14 $(14,76)$ e cultivar R. Du Lot $(8,94)$.

Os resultados do presente trabalho, numa mesma concentração do ácido foram superio-res $(39,33)$, embora deva-se levar em consideração que a cultivar utilizada não foi a mesma.

Resultados obtidos por ALVARENGA (1976), porém com diferentes concentrações de IBA e NAA, também mostram maior facilidade de enraizamento do porta-enxerto "Traviú", em comparação com o IAC 572, Kobber 5BB e o IAC 766.

O Tratamento com IBA $5.000 \mathrm{ppm} /$ minuto resultou na mais baixa porcentagem de enraizamento das estacas (16,67\%), vindo concordar com a citação de MORETTI \& RIDOMI (1983), os quais verificaram que o uso de reguladores de crescimento nas estacas de videira, especialmente em altas concentrações, exerceu, frequentemente, efeitos deletérios à formação de raízes e não pode ser recomendado.

O uso dos fitorreguladores neste trabalho, leve na maioria dos tratamentos, efeitos favoráveis na indução do enraizamento, tendo o IBA 2.000 ppm proporcionado a maior porcentagem de estacas enraizadas $(88,87 \%)$ e com maior comprimento médio $(84,33 \mathrm{~mm}$ ) (Quadro 1).

Entretanto, a simples imersão da base das estacas em água promoveu a formação de raízes em $61,10 \%$ das estacas, confirmando citações de TIZIO et al. (1963) e TERRA et al. (1981). 
TABELA 1. Porcentagem de enraizamento, número médio de raízes formadas por estaca e comprimento médio das raízes, após instalação no mês de julho/1989.

\begin{tabular}{llll}
\hline \hline Tratamentos & \% enraizamento & $\mathrm{n}^{0}$ raízes/estaca & $\begin{array}{c}\text { comprimento das raízes } \\
(\mathrm{mm})\end{array}$ \\
\hline $\mathrm{H}_{2} \mathrm{O}$ & $61,10 \mathrm{a}$ & $53,33 \mathrm{a}$ & $81,03 \mathrm{a}$ \\
$\mathrm{H}_{3} \mathrm{BO}_{3} 150 \mu \mathrm{g} / \mathrm{ml}$ & $77,67 \mathrm{a}$ & $10,66 \mathrm{~b}$ & $27,83 \mathrm{ab}$ \\
IBA $5.000 \mathrm{ppm}$ & $16,67 \mathrm{~b}$ & $12,50 \mathrm{~b}$ & $22,00 \mathrm{~b}$ \\
IBA $2.000 \mathrm{ppm}$ & $88,87 \mathrm{a}$ & $39,33 \mathrm{ab}$ & $84,33 \mathrm{a}$ \\
IBA $5.000 \mathrm{ppm}+\mathrm{H}_{3} \mathrm{BO}_{3}$ & $44,43 \mathrm{ab}$ & $20,16 \mathrm{ab}$ & $36,50 \mathrm{ab}$ \\
IBA $2.000 \mathrm{ppm}+\mathrm{H}_{3} \mathrm{BO}_{3}$ & $77,77 \mathrm{a}$ & $40,83 \mathrm{ab}$ & $67,83 \mathrm{a}$ \\
$\mathrm{NAA} 3.500 \mathrm{ppm}$ & $72,20 \mathrm{a}$ & $34,50 \mathrm{ab}$ & $78,83 \mathrm{a}$ \\
NAA $1.500 \mathrm{ppm}$ & $72,20 \mathrm{a}$ & $60,50 \mathrm{a}$ & $60,66 \mathrm{ab}$ \\
IBA $1.000 \mathrm{ppm}$ & $61,50 \mathrm{a}$ & $14,30 \mathrm{~b}$ & $29,56 \mathrm{ab}$ \\
IBA $1.000 \mathrm{ppm}+\mathrm{H}_{3} \mathrm{BO}_{3}$ & $44,80 \mathrm{ab}$ & $11,91 \mathrm{~b}$ & $51,22 \mathrm{ab}$ \\
\hline & $\mathrm{F}=4,85 *$ & $\mathrm{~F}=4,95 *$ & $\mathrm{~F}=4,93 *$ \\
\hline \hline
\end{tabular}

* = nível de significância é $5 \%$

Médias seguidas de mesma letra não diferem entre si.

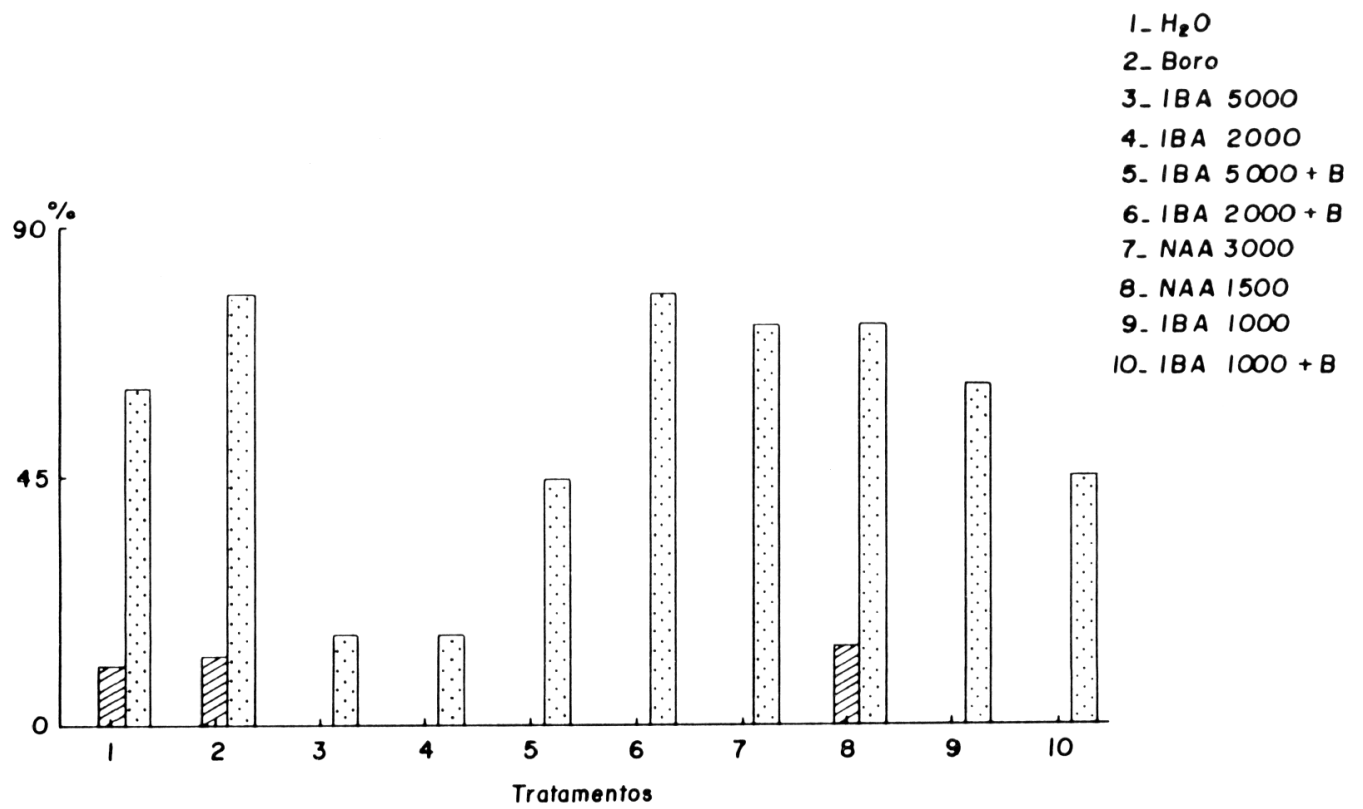

Figura 1. Porcentagem de enraizamento após instalação nos meses de janciro, abril e julho de 1989.

Sci. agric., Piracicaba, 50(1):27-32, fev./maio, 1993 
Com relação à suplementação de boro, verificou-se que nos tratamentos IBA 1.000 e 5.000 $\mathrm{ppm}+\mathrm{H}_{3} \mathrm{BO}_{3} 150$ microgramas $/ \mathrm{ml}$ houve incrementos na porcentagem de enraizamento, no comprimento das raízes e no número de raízes formadas por estaca, quando comparados com o IBA sozinho. JARVIS et al. (1984), observaram em estacas de $P$. aureus aumento do desenvolvimento das raízes, com o aumento da concentração de IBA, principalmente quando essas estacas eram tratadas $\mathrm{com}$ ácido bórico à 150 microgramas $/ \mathrm{ml}$, o que levou ao máximo de crescimento das raízes.

\section{CONCLUSÕES}

Através dos resultados obtidos. for possivel concluır que o ácido indol-butírico (IBA $2.000 \mathrm{ppm} / \mathrm{um}$ minuto), for o tratamento que proporcionou a mator porcentagem de estacas enraizadas $(88,87 \%)$, porém este não diferiu estatisticamente da testemunha $\left(\mathrm{H}_{2} \mathrm{O}-61,10 \%\right)$. A melhor época para o enrazamento de estacas de porta-enxerto "Rıparıa do Traviú" ou "Travıú" de videira (Viths vinffera L.), correspondeu ao mês de julho (inverno).

\section{REFERÊNCIAS BIBLIOGRÁFICAS}

ALCÂNTARA, V. de B.G . ABRAMIDES, P.L.G.: ALCANTARA. PB Apliaşào de auma e estimulantes no enrazamento de estacas de leuiena. jureminha. guandu e amoreıra. Boletim de Indústria Animal. Nova Odessa. + 40. n 2. p.279-281. 1983

ALVARENGA. L R. Estudos do enraizamento de quatro varbedades de porta-enxertos de videra com o emprego do ácido indol-butírico In CONGRESSO BRASILEIRO DE FRUTICULTURA, 3 . 1975. Rio de Janeiro, Anais ... Campinas Sociedade Brasileıra de Fruticultura, 1976. v.2. p 597-602.

ALVARENGA, L.R : FORTES. J.M Enraizamento e desenvolvimento aćreo de alguns porta-envertos de videira no município de Viģosa In. CONGRESSO BRASILEIRO DE FRUTICULTURA.3., 1975. Rio de Janeiro, Anais Campinas Sociedade Brasileita de Fruticultura, 1976. v.2. p.591-596

ELLIASSON, L. Effects of nutrients and light on grow th and root formation in Pistum sarrwm surlings. Physiology Plantarum. Copenhagen, v.43, p.13-18. 1978.

FADL, M.S.; HARTMANN. H.T. Relatonship between seasonal changes in endogenous promoters and
Inhibitors in pear buds and sutting bases and the rooting of pear harduood outtings. Proceedings of the America Society for Horticultural Science. Alexandria. . 91. p.96-112.1967.

GALVÃO, A. de O.: SILVA. A.Q.: SILVA. H. Efeito dos fitohomónios. IBA. ANA no enraizamento de estacas de umbuzeiro. In: CONGRESSO BRASILEIRO DE FRUTICULTURA, 9., 1987. Campunas. Anais... Campinas : Sociedade Brasileira de Fruticultura. 1987. p.703-709.

HARTMANN, H.T.: HANSEN. C.J. Rooting of softuood cuttings of several fruits species under mist. Procedings of the American Society for Horticultural Science. Alexandra, r.66. p.157-167. 1955.

HARTMANN.H.T.: KESTER. D E Plant propagation prineiples and practices. New York. Englew ood Clipfs. Prentice-Hall. 1983, 727p

HIRSCH. A.N.: PENGELLY, W.L. TORREY'. I G Endogenous IAA levels in boron-defielent and control root tips of sunflower Botanical Gazette. Chwago. ง.143. p 15-19.1982.

IVANIKA, J.: PASTYRIK, L. The utilization of 3-indolebutyric acid in rooting hardwood cutnng of fruit trees. Acta Horticulturae. Wageningen. 1.80. p.83-85. 1978 .

JARVIS, BC, YASMIN, S: ALI, A.H.N. The interation berween auyn and horon in adventious roor derelopnent. Yew Plytologist. Cambrige. v.97. n 2. p 197-204. 1984

KERSTEN. E. Propagaçāo legetativa dos eitros for métodos não convencionals. Prackiata Escola Superior de Agrivulura "Luiz de Queiroz". 1987 20p (Mlimeogr.).

LANPHEAR. F.O.. MEAHL. R.P. Influenees of endogenous rooting cofactors and environment on the seasonal fructuation in root intuation of selested evergreen suttugs Procedings of the American Society for IIorticultural Sience. Alexandna. 1.77 . p 620-634. 1963

LEWIS, DH Boron. lignitication and the origin of vascular plants - a unified hypothesis. New Phy tolngist. Cambndge. v.84. n.2. p.209-229. 1980

MORETTI. G.; RIDOMI, A. The effects of growth regulators on the propagation of grapevines from grafted cuttings. Riv. Vitic. Enol., Conegliano. v.36. p. $453-469.1983$ 
PEREIRA, F.M.; ABE, M.E.; JUNIOR, MM. et al. Influência da época de estaquia, em recipiente, no pegamento e desenvolvimento de estacas de figueira (Ficus carica L.). In: CONGRESSO BRASILEIRO DE FRUTICULTURA, 1., 1971. Campinas. Anais... Campinas: Sociedade Brasileira de Fruticultura, 1973. p.446-450

RIBAS, W.E.; CONAGIN, A. Variedade de cavalos de videira e sua melhor época de enraizamento. Bragantia, Campinas, v.16, p.127-138, 1957.

SANTOS NETO, J.R.A. A Cultura da Videira. Campinas : Instituto Agronômico, 1973. 108p.

SILVA, A.P.L. da; FACHINELLO, J.C.; MACHADO, A.A. Efeito do ácido indolbutírico na enxertia e enraizamento da videira. Pesquisa Agropecuária Brasileira, Brasília, v.21, n.8, p.865-871, 1986.

SOUZA, J.S.I.de; AMARO, A.A.; PINHEIRO, E.de D. Uvas para o Brasil. São Paulo : Melhoramentos, 1969. $454 p$.

TERRA, M.M.; FAHL. J.L.; RIBEIRO, I.J.A.; PIRES, E.J.P.; MARTINS, F.P.; SCARANARI, H.J.; SABINO, J.C.. Efeito de reguladores de crescimento no enraizamento de estacas de 4 porta-enxertos de videira. In: CONGRESSO BRASILEIRO DE FRUTICULTURA, 6., 1981, Recife. Anais ... Recife : Sociedade Brasileira de Fruticultura, 1981. p.1265-1271.
TIZIO, R.; ALMELA PONS, G.; TRIONE, S.O; TRIPPI, V.S. Estudios sobre o enraizamiento en vid. VII. Auxinas, inhibidores y la capacidad rizógena de las estacas. Phyton, Buenos Aires, v.20, n.2, p.1-12, 1963.

WEAVER, R.J. Reguladores del crecimiento de las plantas en la agricultura. 2.ed. Barcelona : Trillas, 1982. 540p.

ZANIN, E.S. Eficiência de diferentes métodos de propagação vegetativa de nespereira (Eriobotria japonica Lindl.) em câmara de nebulização. Jaboticabal, 1985. (Graduação) - Faculdade de Ciências Agrárias e Veterinárias, Universidade Estadual Paulista "Julio de Mesquita Filho".

Trabalho entregue para publicação em 22.05 .92

Trabalho aprovado para publicação em 04.09.92 